\title{
Predicting the temperature and strength development within cemented paste backfill structures
}

\author{
M. Fall Department of Civil Engineering, University of Ottawa, Canada \\ O. Nasir Department of Civil Engineering, University of Ottawa, Canada
}

\begin{abstract}
In this paper, a thermo-chemo-mechanical (TCM) model is developed and implemented into FLAC software for predicting the strength development and distribution within hydrating cemented paste backfill (CPB) structure, temperature development and distribution within the CPB structures, heat transfer between CPB structures and mine rock temperatures. The developed model is validated against results from laboratory (on $C P B$ samples and small scale model) and field studies of CPB. The validation tests show good agreement between the predicted and experimental laboratory and field results. The developed tool is then used to simulate the performance of $C P B$ structure in several practical cases of mine backfill operations. From the simulation results valuable information was gained regarding the strength and heat development within $C P B$ structures, the optimal curing time of a given CPB structure, the effect of filling rate and stope geometry of the strength and heat development within $C P B$ structures, the effect of mix design (e.g. \%binder, water content, initial mix temperatures, tailings types) on the performance (mechanical, thermal) of $C P B$ structures. The developed tool will contribute to more cost-effective and safer design of CPB structures.
\end{abstract}

\section{Introduction}

Cemented paste backfill (CPB) receives great interest as one of the most commonly used ways in mine backfilling around the world. The usage of CPB greatly contributes to the disposal of mining tailings waste from the surface, increasing working place stability and having the ability to extract more minerals safely. Although CPB has been successfully implemented in underground mining operations worldwide, it remains a relatively new technology. The industry is still on a learning curve with respect to the performance properties and optimal design of CPB structures. The field behaviour and many design criteria of CPB structures are still not well understood. For example, there is still not enough available technical information to address the following key design decisions in a cost-effective way: What is the strength development and distribution within a CPB structure? What is the optimal curing time of a given CPB in the field? What is the optimal filling rate and strategy for a given CPB structure? What is the temperature development and distribution within a CPB structure and its impact on the CPB behaviour? What is the optimal mix design and stope geometry (e.g. size, shape) for a given CPB structure? To address these design challenges in a cost-effective way the understanding and modelling of the coupled processes (thermal, chemical, hydraulic, mechanical) that occur in CPB are crucial. This is also necessary for reliably assessing and predicting the performance of CPB structures. In this paper, a numerical tool (implemented into FLAC software), based on TCM modelling approach, is developed for predicting the strength development and distribution within hydrating CPB structure, temperature development and distribution within the CPB structures, heat transfer between $\mathrm{CPB}$ structures and mine rock temperatures as well as to address the key aforementioned design issues of $\mathrm{CPB}$.

\section{Model development and validation}

\subsection{Modelling approach}

FLAC (2D) (Version 5.0, Itasca, 2005), a two-dimensional finite difference program based on an explicit Lagrangian calculation scheme, was used for the numerical modelling. Explicit means it uses a time stepping procedure to solve the problem without forming the stiffness matrix. Furthermore, the program FLAC contains a powerful built-in programming language (FISH), which enables the user to implement his own 
functions or constitutive models, define quantities to be calculated and to control the analysis processes. Thus, a TCM model was developed and then implemented into FLAC to predict and study the TCM response of $\mathrm{CPB}$ structure. The $\mathrm{CPB}$ was assumed as fully saturated and in undrained conditions (conservative assumptions). The model is based on the coupling of following processes (Figure 1):

- Chemical processes (C); they describe and capture the chemical reactions (binder hydration) that occurs in hydrating undrained CPB structure.

- Thermal processes $(\mathrm{T})$; they describe and capture heat generation and transfer within the $\mathrm{CPB}$ structures as well as the evolution of the thermal properties of the CPB.

- Mechanical processes (M) (limited to strength); they describe and predict the unconfined compressive strength (UCS) development and distribution within the undrained CPB structures. The UCS is the key parameter for the design of CPB structure from the mechanical stability point of view.

- CPB Filling processes (F); to take into account the effect of the CPB filling rate on the TCM processes. From the numerical point of view, this backfilling rate is converted by a simple calculation into the rate of increase in the height of the backfill structure, and then to a change in the elements properties.

Most of the mathematical equations used in the development of the TCM are external equations ('User Defined' equations; i.e. are not FLAC built), which are implemented into FLAC by using the FISH language. These implemented equations will allow taking into account, several mechanisms in the model, such as the binder hydration process, the CPB mix components, stope geometry, model generation, temperature, curing time, rate of backfilling and some other processes. The mathematical approaches and equations used to develop the TCM model are given in Fall and Nasir (2009), Nasir and Fall (2009a, 2009b).

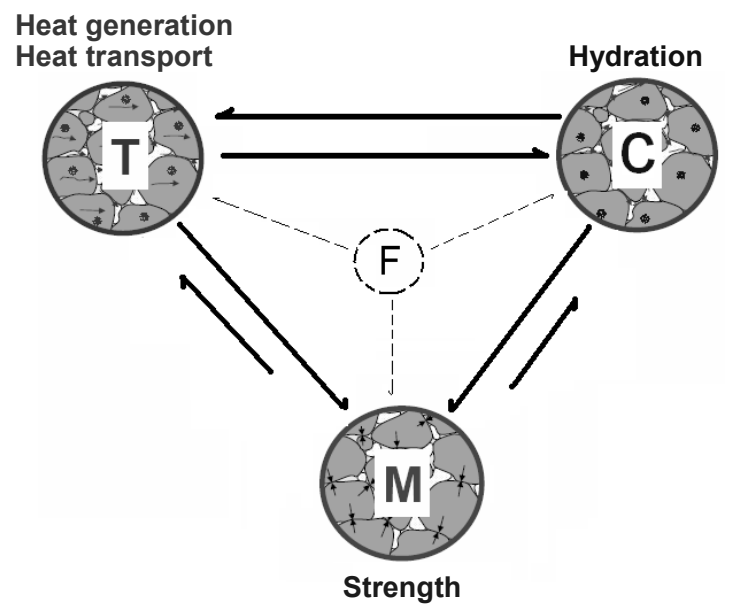

Figure 1 Schematic representation of the main coupled TCM factors in hydrating undrained CPB structure considered in this study. F: Filling rate of the CPB; long arrow: strong coupling; short arrow: weak coupling; dashed arrow: one way effect

\subsection{Model validation}

To validate the results of the developed FLAC model three categories of experimental data were used: (i) data from experimental tests performed on various types CPB samples (from different mines, different mix components) at the University of Ottawa and in other laboratories; (ii) data obtained from tests performed on small scale model of CPB; (iii) field data. The validation results have shown that there is good agreement between the predicted and experimental results, i.e. the ability of the developed FLAC model to predict the UCS, temperature and binder hydration development of different types of undrained CPBs. Some results of the validation are presented in Figures 2 and 3, whereas further results are published elsewhere (e.g. Fall and Nasir, 2009; Nasir and Fall, 2009a, 2009b). Figure 2 shows a comparison of the temperature development predicted by the developed model and that recorded within a CPB structure in the field at the 
Lucky Friday Mines (Williams et al., 2001). Generally, the comparison shows a good agreement between the developed model and the $\mathrm{CPB}$ temperature development in the field, especially with the maximum temperature. Otherwise, the differences in temperature may be due to the varied boundary conditions in the field.

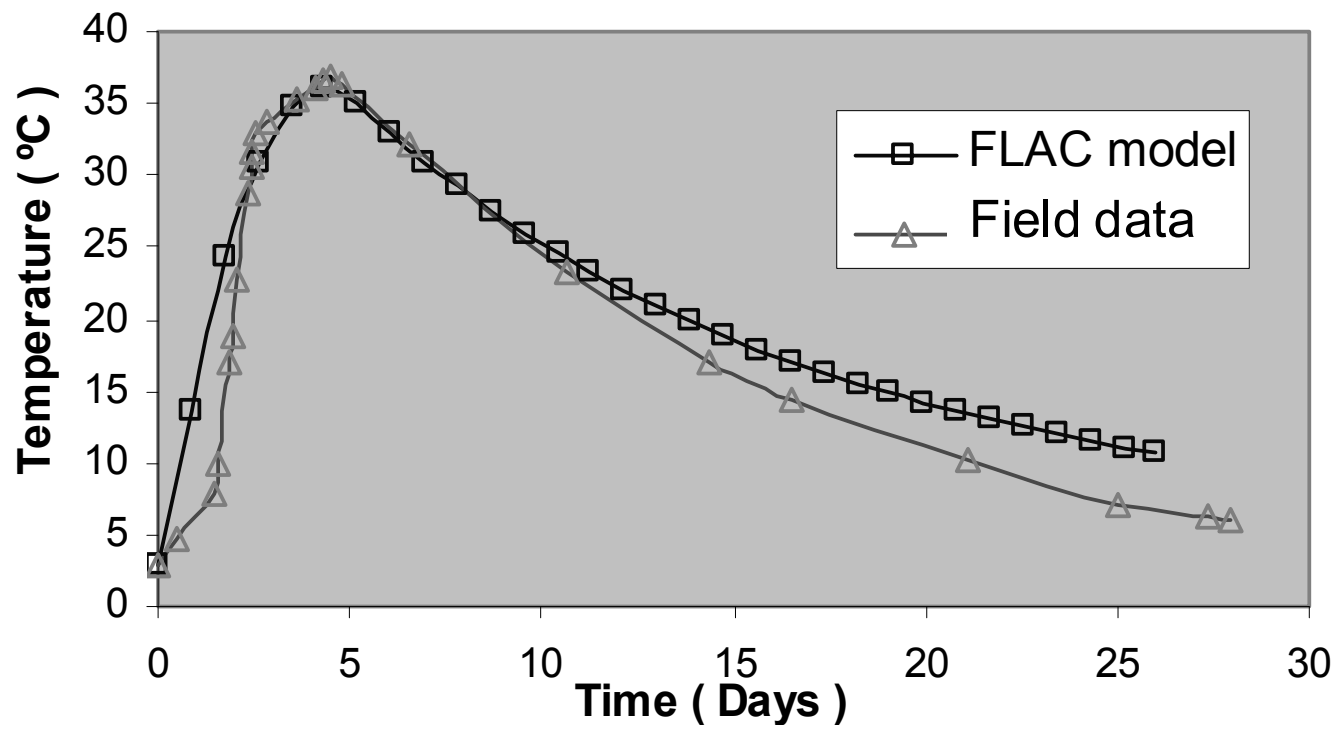

Figure 2 Comparison between the predicted and measured (example 1) temperature development within the CPB structure in the field

Figure 3 shows an example of validation results of the UCS development of CPB. It shows a comparison between the experimental results and developed FLAC model results. The results are presented in the form of normalised strength (UCSt/UCS28). A set of available experimental results for the development of UCS for various cemented backfill materials (originated from different mines) was used for validation purposes (e.g. Yilmaz et al., 2004; Fall and Samb, 2008; Fall et al., 2004, 2008; Celestin, 2008; Pokharel, 2008). The results show good agreement between the predicted and experimental results, i.e. the ability of the developed model to predict the UCS development of different types of undrained CPBs.
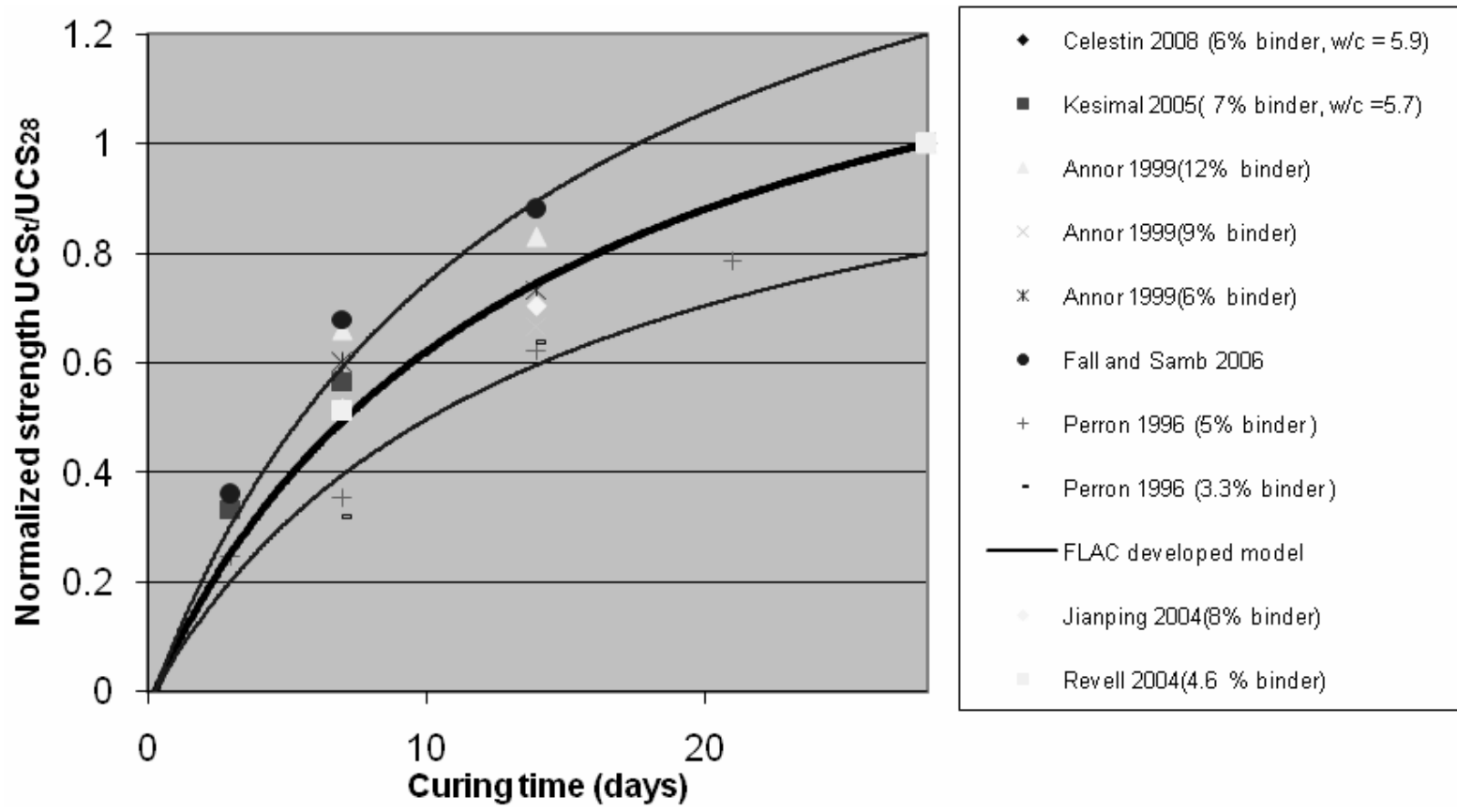

Figure 3 Comparison between the predicted and experimental UCS 


\section{Model applications}

After the validation of the developed model with different case studies, the model was applied to simulate the performance (e.g. strength development, thermal response, heat transfer, thermal interaction with the rock mass) of CPB structures in various conditions (mine climates, influencing different factors). The factors were selected to study the effect of stope geometry (size, shape, angle and height), initial CPB and rock temperature, binder consumption, rate of backfilling, curing time, CPB mix components (e.g. tailings types, binder content) and rock thermal properties on the development of the performance (e.g. strength, temperature) of CPB structures. Valuable results were obtained regarding the thermal-chemical-mechanical response of CPB structure and its optimal design. Some samples of simulation results are presented and discussed below.

\subsection{Effect of stope geometry on the temperature and strength development within CPB structures}

Since the geometrical characteristics (stope size, shape, angle, height) of a backfilled stope can largely vary, the effect of the CPB geometry on the strength and temperature development as well as binder hydration were investigated by considering different geometries. The results show that the stope size has a significant effect on the strength and temperature development within the CPB structure. Some illustrative examples of the effect of stope size on the development and distribution of temperatures and strength within the CPB structures are presented in Figures 4 and 5, respectively. The effect of CPB structure size was investigated by selecting a range of stope sizes (from $0.5 \times 1 \mathrm{~m}$ to $10 \times 20 \mathrm{~m}$ ). In this case, the binder content is $100 \mathrm{~kg} / \mathrm{m}^{3}$, the initial CPB temperature is $20^{\circ} \mathrm{C}$, and the backfill rate is $2.5 \mathrm{~m} /$ day. From these figures, it is clear that the stope size has a significant effect on the temperature and strength development and distribution within the $\mathrm{CPB}$ structure as well as the cooling rate of the $\mathrm{CPB}$ structure. It can be observed from Figure 4, that increasing the stope size will increase the amount and rate of temperature rise. This is because as the size of the backfill structure increases, the volume of hydrating cement phases increases, thereby leading to more heat production. The heat generated will lead to faster chemical or binder reaction according to Arrhenius' law. Figures 5 shows both the strength development and distribution within the CPB stope. Strength is represented by the percentage gained of ultimate strength. Increasing the stope size will increase the strength developed, especially at the lower and middle part of the stope, while with a smaller size, the strength will be lower and more homogenous. The main reason is that increasing the size will lead to more heat production induced by the cement hydration (due to the increase in volume of hydrating cement phases increases) as well as delay the heat transfer from the hydrated CPB to the surroundings, which leads to the accumulation of heat and increase in temperature, which then results in increase in strength. In opposite to the stope size, the results show that the slope angle of a CPB structure has a negligible effect on the development and distribution of temperature (Figure 6) and strength within CPB structures as well as on the heat transfer between hydrating the CPB and the stope wall. 


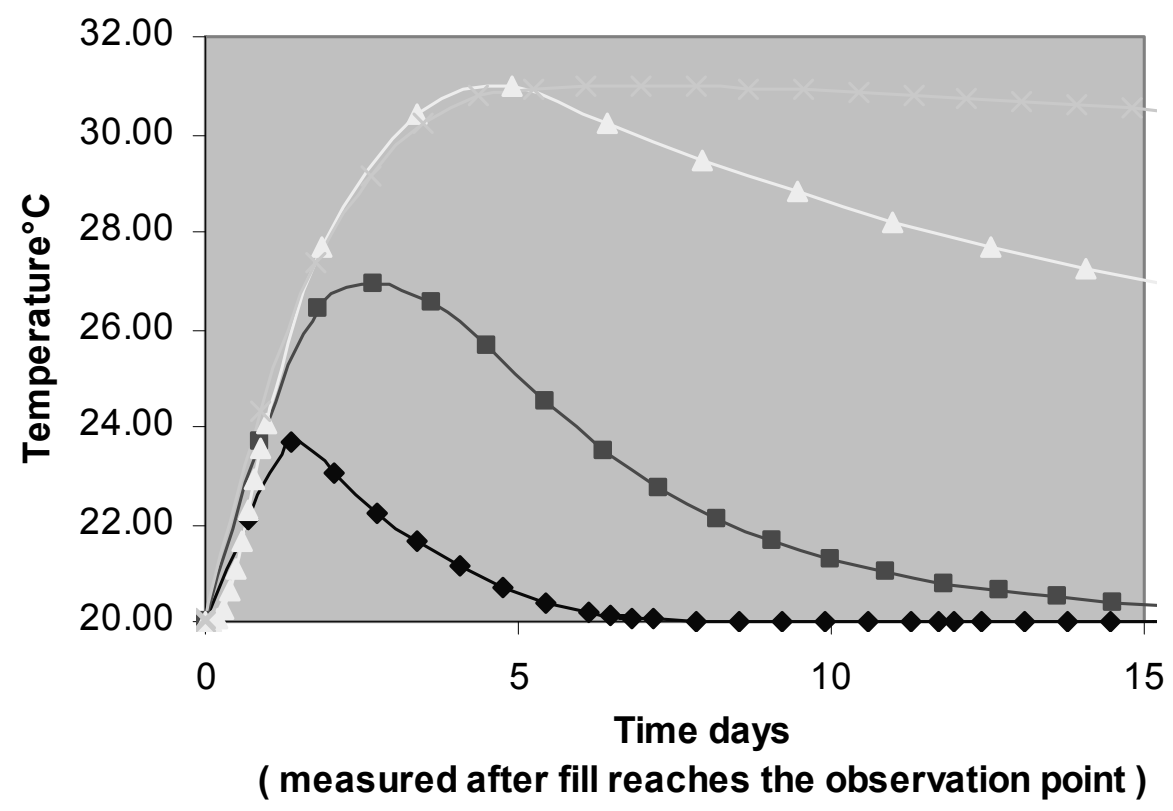

\section{Stope size \\ $\mathbf{m} \times \mathbf{m}$}

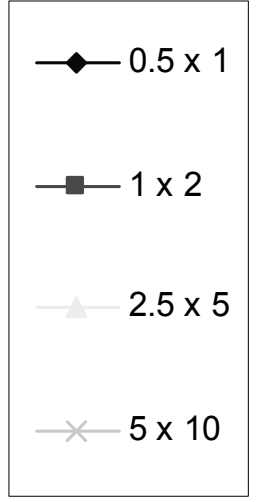

Figure 4 Effect of stope size on the heat development within CPB

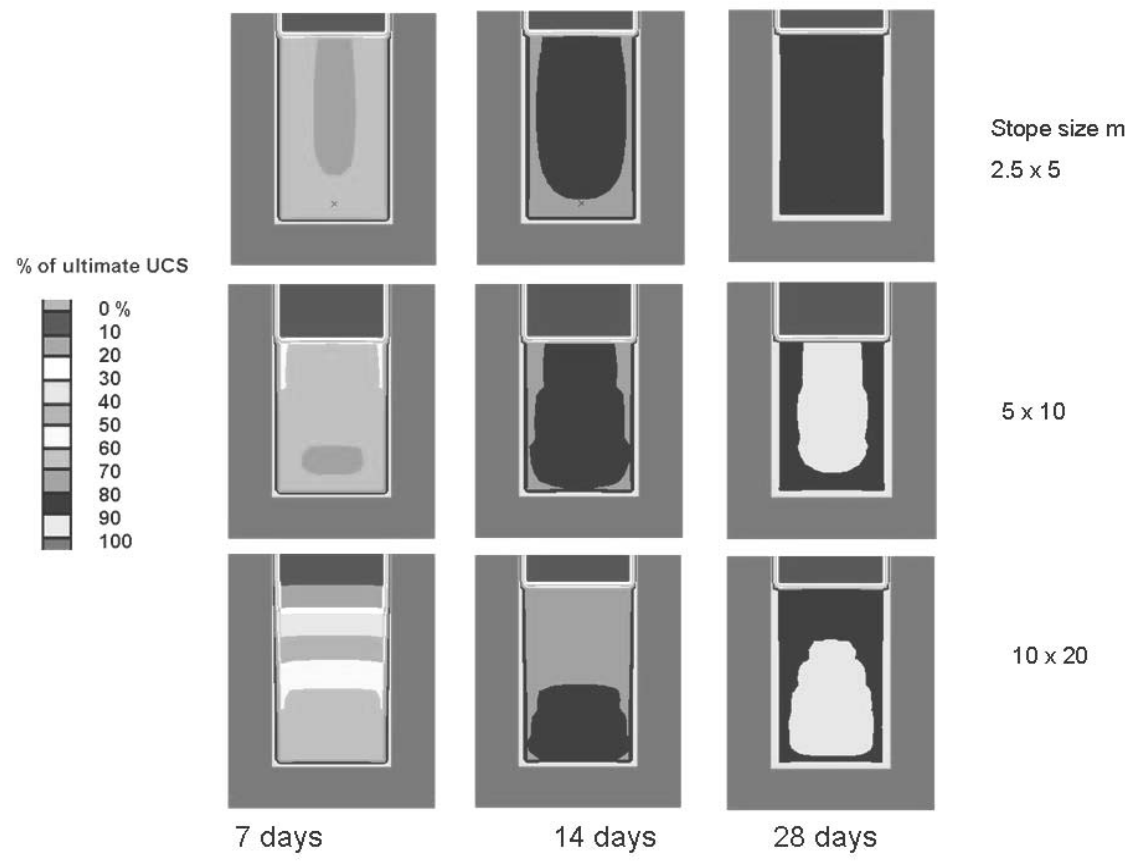

Figure 5 UCS development for different stope sizes (mix characteristics per Fall and Samb, 2008; rate of backfilling $2.5 \mathrm{~m} /$ day) 


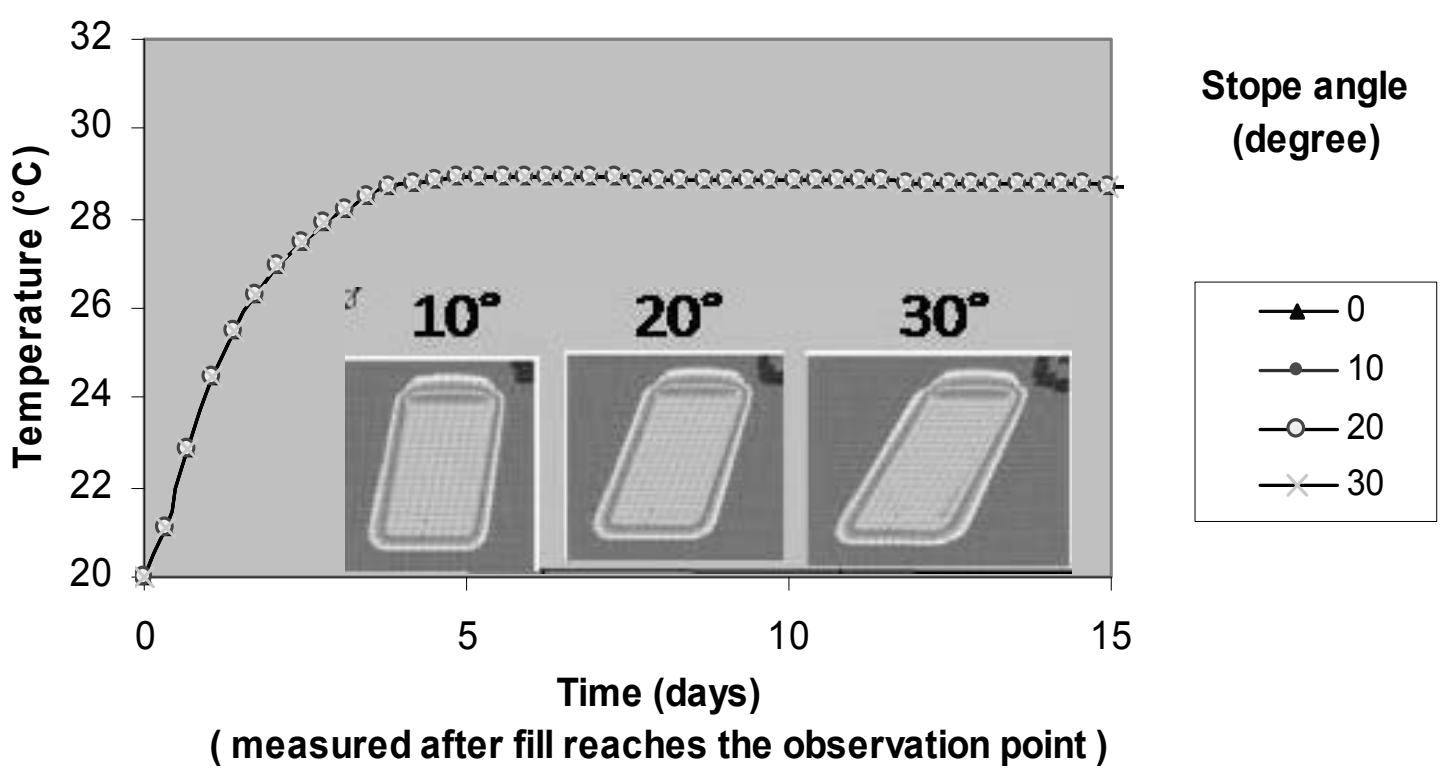

Figure 6 Effect of stope angle on the heat development of CPB

\subsection{Effect of mix components on the development and distribution of temperature and strength within CPB structures}

The main components of CPBs include the binder, mixing water and tailings. The nature (e.g. chemical and physical characteristics) and amount of these components used to prepare CPB materials in the mine plants vary greatly. Therefore, the effects of the mix components of CPBs and their variations on the performance of CPB structures were numerically investigated. As expected the simulation results show the CPB mix components can significantly affect the development and distribution of temperature and strength within the CPB structure. For example, Figures 7 and 8 illustrate the effect of binder content (which has a considerable contribution on the overall cost of mine backfilling) on the development and/or distribution of temperature and strength within the CPB structures, respectively. The effect of binder content on the strength development of CPB was investigated by taking a range of binder content values: 50,100 and $200 \mathrm{~kg} / \mathrm{m}^{3}$, with a stope size of $10 \times 20 \mathrm{~m}$ for two cases using different mix properties for each case. The results show, as expected, that binder content has a significant effect on the temperature and strength development and distribution within CPB. The early age strength is strongly affected by the binder content. This is mainly due to the fact that higher binder content is associated with more precipitation of binder hydration products (e.g. CSH: major responsible for the strength development of cemented materials) and with higher cement hydration heat (heat accelerates the binder hydration). Figure 5 and 9 show the strength development and distribution within CPB made of the same binder type and content, but of tailings with different physical and chemical characteristics. It can observed, that regardless of the CPB size, despite using the same binder content in volume, each mix shows a different response. The difference can be attributed to various factors such as the grain size distribution, mineralogical composition of the tailings, and the sulphate content. 


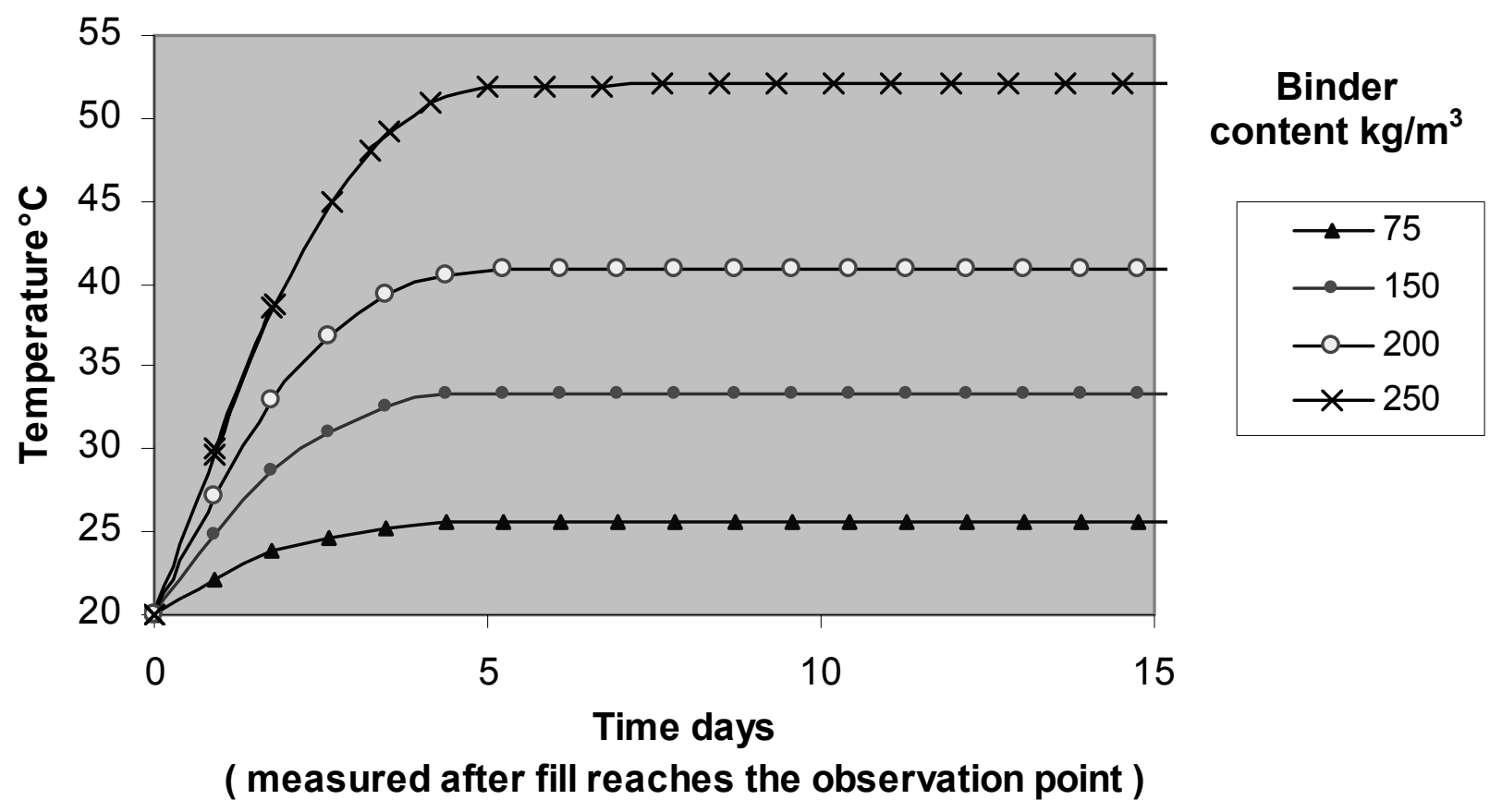

Figure 7 Effect of binder content on the heat development of CPB

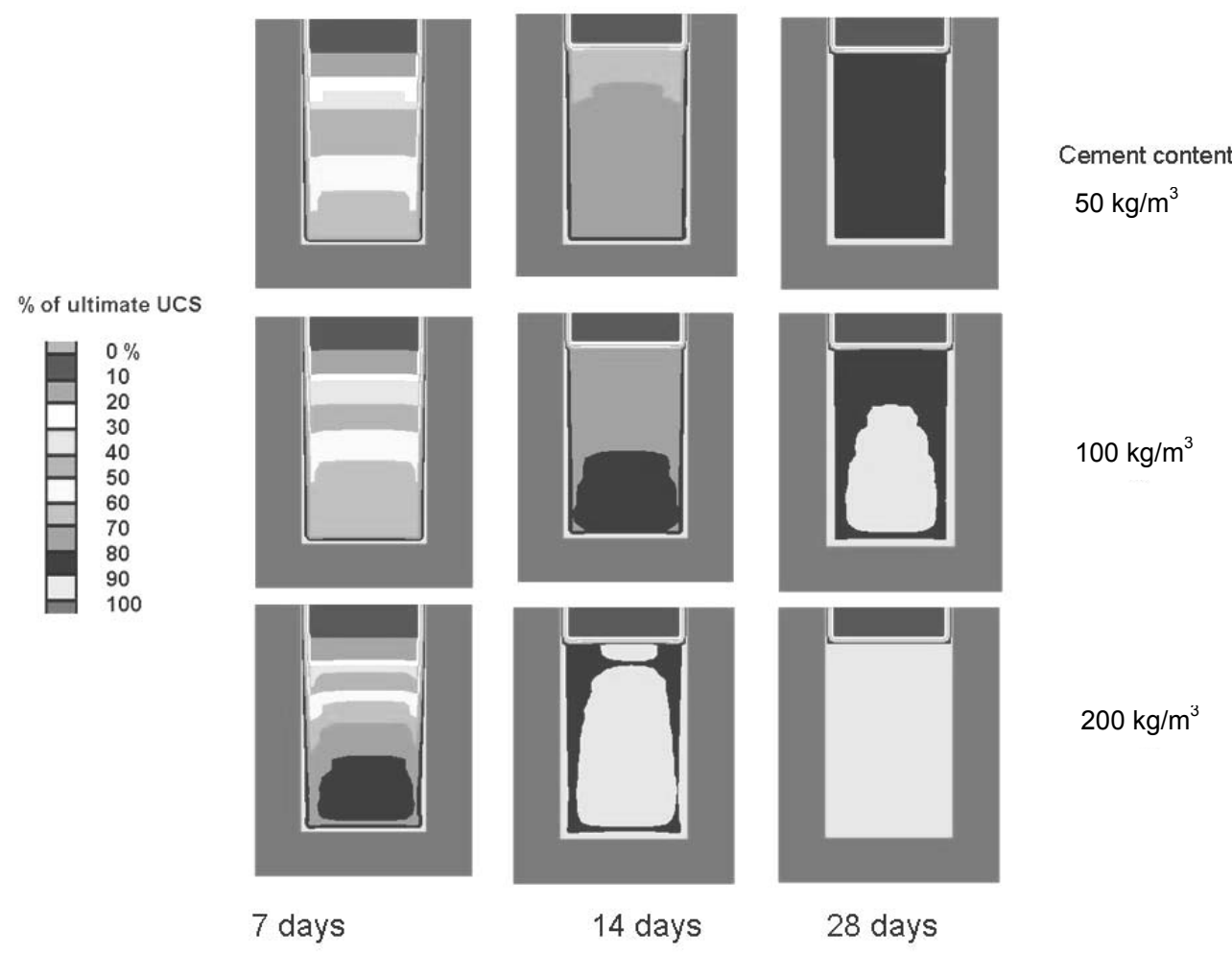

Figure 8 UCS development for different binder content (mix characteristics per Fall and Samb, 2008; rate of backfilling $2.5 \mathrm{~m} /$ day) 


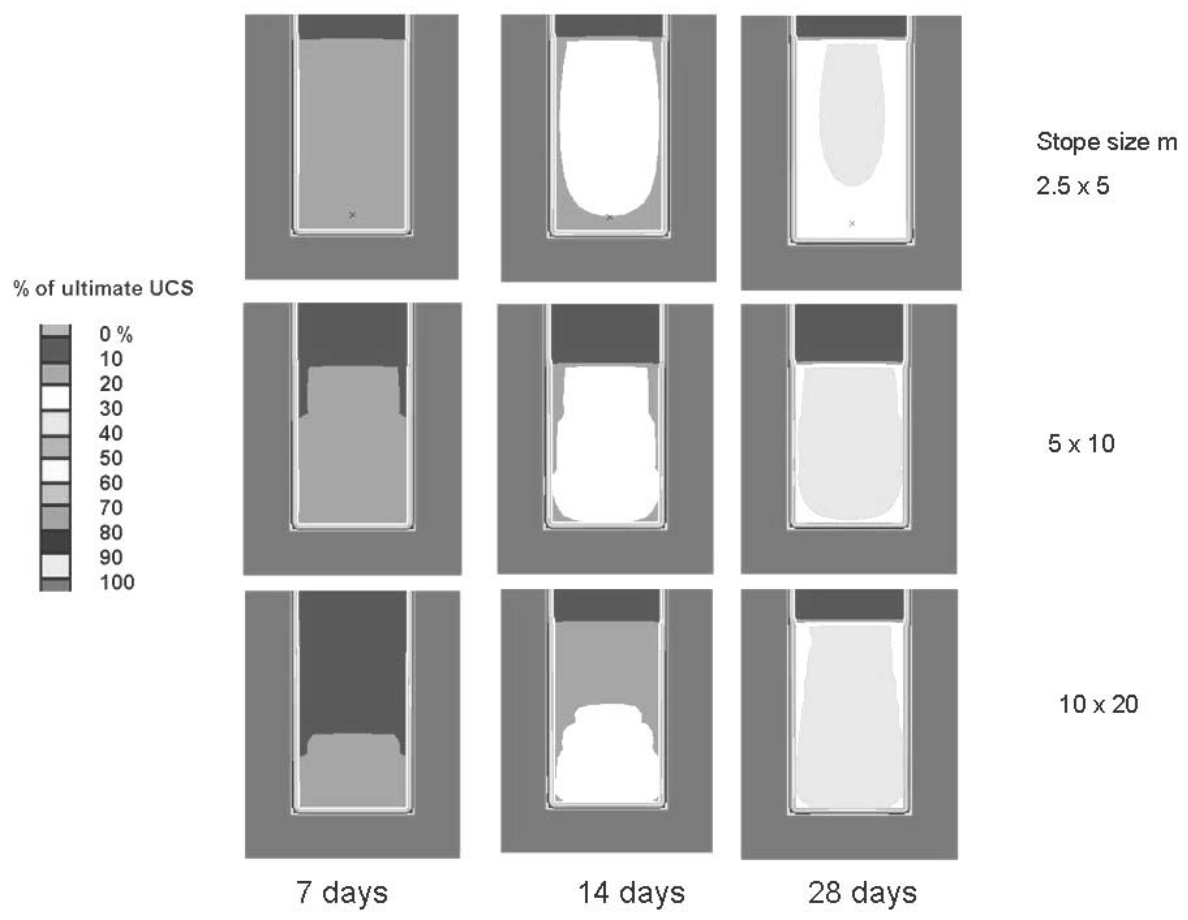

Figure 9 UCS development for different stope sizes (mix characteristics per Celestin, 2008; rate of backfilling $2.5 \mathrm{~m} /$ day) (compare this figure with Figure 5)

\subsection{Effect of the rate of backfilling on the temperature and strength development within CPB structures}

To study the effect of rate of on the development and distribution of temperature and strength within a CPB structure, a range of rates of backfilling of $1 \mathrm{~m} /$ day, $2.5 \mathrm{~m} /$ day, $5 \mathrm{~m} /$ day and $10 \mathrm{~m} /$ day with stopes of various sizes $(5 \times 10 \mathrm{~m}, 10 \times 20 \mathrm{~m}, 30 \times 60 \mathrm{~m})$ and a CPB's cement content of $75 \mathrm{~kg} / \mathrm{m}^{3}$ were considered. An example of simulation results regarding temperature development is presented in Figure 10, while Figure 11 illustrates the effect of the rate of backfilling on the strength development and distribution within the CPB structure after 28 days of curing for a CPB with mix characteristics given by Fall and Samb (2008). From Figure 11, it is clear that the rate of backfilling has a significant impact on the strength development and distribution within the CPB structure. It can be observed that a low rate of backfilling leads to a significant variation in the distribution of 28 days UCS within the CPB structure. On the other hand higher rate produces more uniform distribution of UCS and a larger part of the CPB structure with high strength. These observations are in good agreement with the fact that higher backfill rate is associated with higher temperature rise (Figure 10). This is because faster filling will reduce the loss of heat through the surroundings (Nasir and Fall, 2009a). Practically, this will provide a higher curing temperature and higher early age strength. However, the effect of rate of backfilling is less significant as the rate of backfilling exceeds $5 \mathrm{~m} /$ day in the studied case (i.e. stope size and cement content); indeed, it can be observed that the stopes backfilled with a rate of $5 \mathrm{~m} /$ day and $10 \mathrm{~m} /$ day show relative similar strength distribution and values. This can be attributed to the fact that as the filling rate becomes large, during hydration of the CPB structure, the rate of heat generation far exceeds the rate of dissipation to the surroundings. 


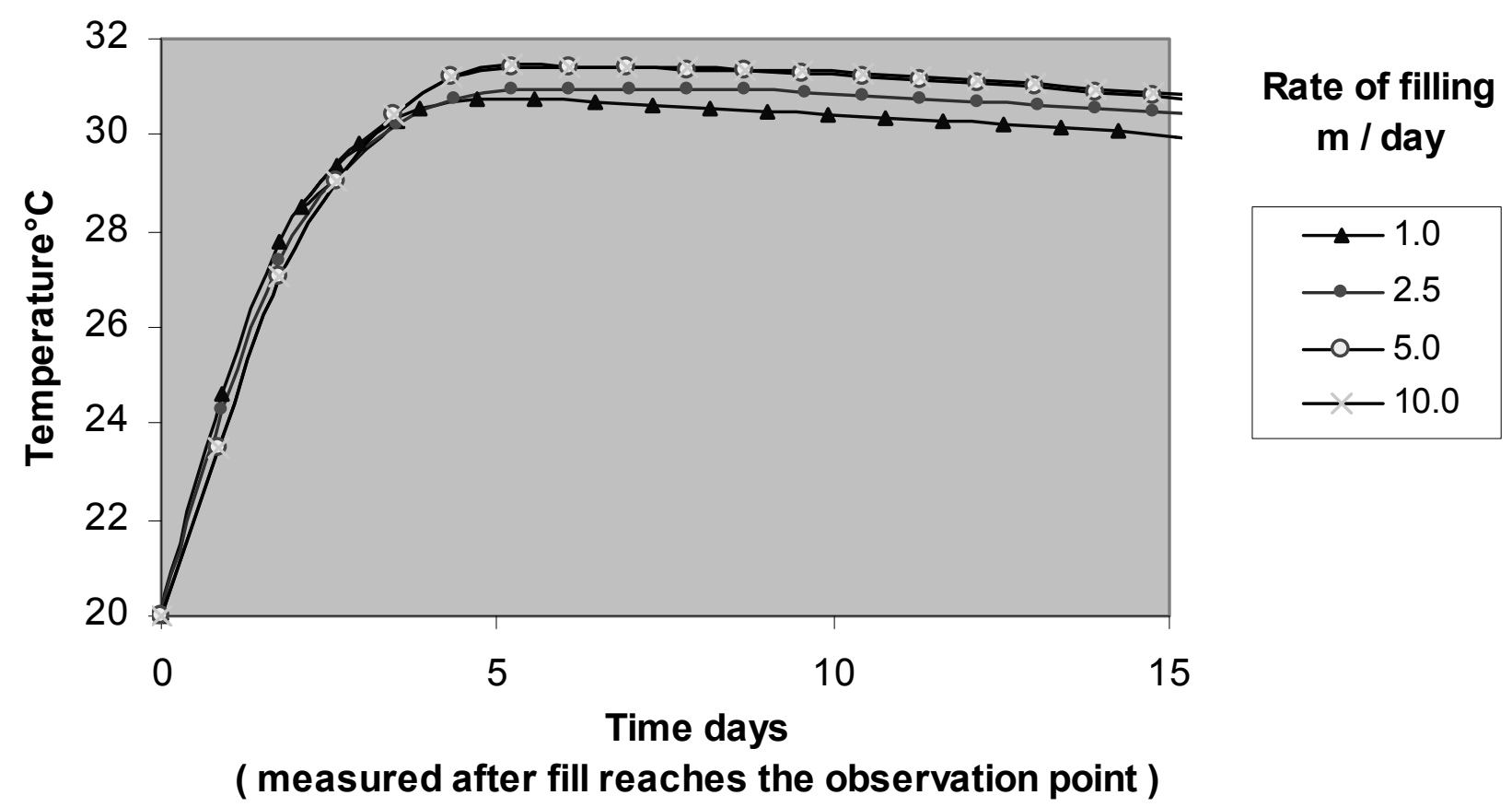

Figure 10 Effect of rate of backfilling on the heat development of CPB for a small stope of $5 \times 10 \mathrm{~m}$ at $2.5 \mathrm{~m}$ above the bottom of the stope

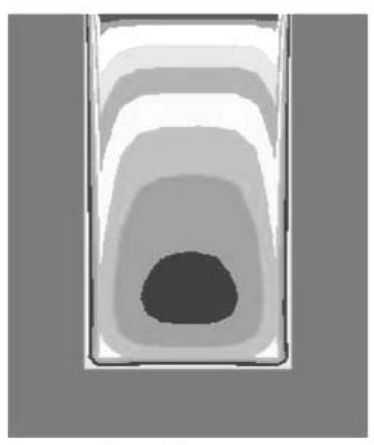

$1 \mathrm{~m} / \mathrm{day}$

$\%$ of ultimate UCS

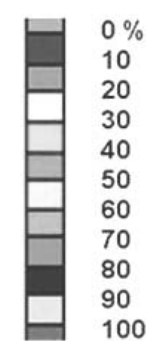

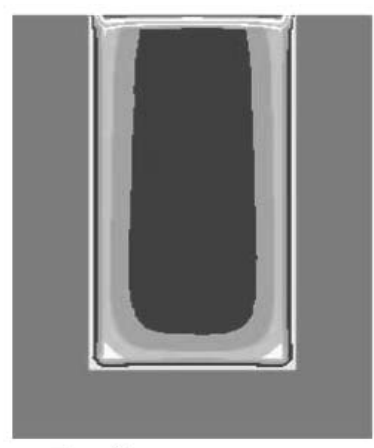

$5 \mathrm{~m} /$ day

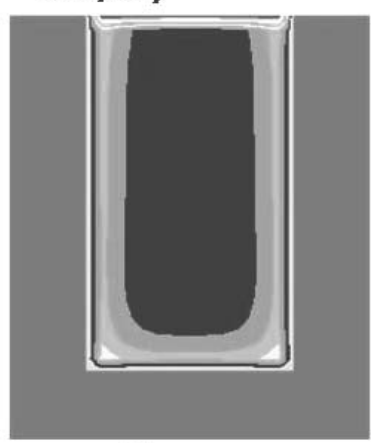

$10 \mathrm{~m} /$ day

Figure 11 UCS development at 28 days for different rates of backfilling (mix characteristics per Fall and Samb, 2008)

\subsection{Effect of the initial CPB temperature on the development and distribution of temperature and strength within $C P B$ structures}

In the field, the CPB initial temperature is strongly influenced by the initial temperature of tailings and water used to prepare it. Different environmental temperatures from one location and/or from one season to another can significantly affect the tailings and water temperature used to prepare $\mathrm{CPB}$ and hence, the initial CPB 
temperature. Furthermore, as ore reserves available at shallow depths are becoming rare in several countries (e.g. Canada, South Africa), underground mining operations are moving to greater depths. This is naturally associated with heat influx increases because of the geothermal gradients. This heat may affect the initial CPB temperature. Hence, the effect of the initial backfill temperature on the rise and distribution of temperature and strength within the $\mathrm{CPB}$ structures was analysed. A range of initial $\mathrm{CPB}$ temperatures from 2 to $50^{\circ} \mathrm{C}$ was selected for the analysis. Selected simulation results are presented in Figures 12 and 13. Figure 12 shows the effect of the initial temperature of the CPB on the heat development at point (p) located $2.5 \mathrm{~m}$ above the bottom of the stope. As expected, a higher initial temperature results in higher temperature rise. This is because high temperatures accelerate the dissolution of the anhydrous clinker phases and thus, the cement hydration process. For this reason, CPB cured at higher temperatures produces more heat and at a faster rate than those cured at lower temperatures. Figures 13 shows the effect of the initial temperature of the $\mathrm{CPB}$ on the strength development and strength distribution within the CPB structure. Results show that increasing the initial $\mathrm{CPB}$ temperature from 0 to $20^{\circ} \mathrm{C}$ will increase the strength by $60 \%$ as shown in Figure 4 . The effect of the initial CPB temperature is obvious mainly during the very early ages ( 7 days). The strength increase with temperature can be attributed to two reasons. First, the accelerated chemical reaction, and hence, higher hydration and secondly, the higher self-desiccation, which leads to higher suction pressure, resulting in a higher strength.

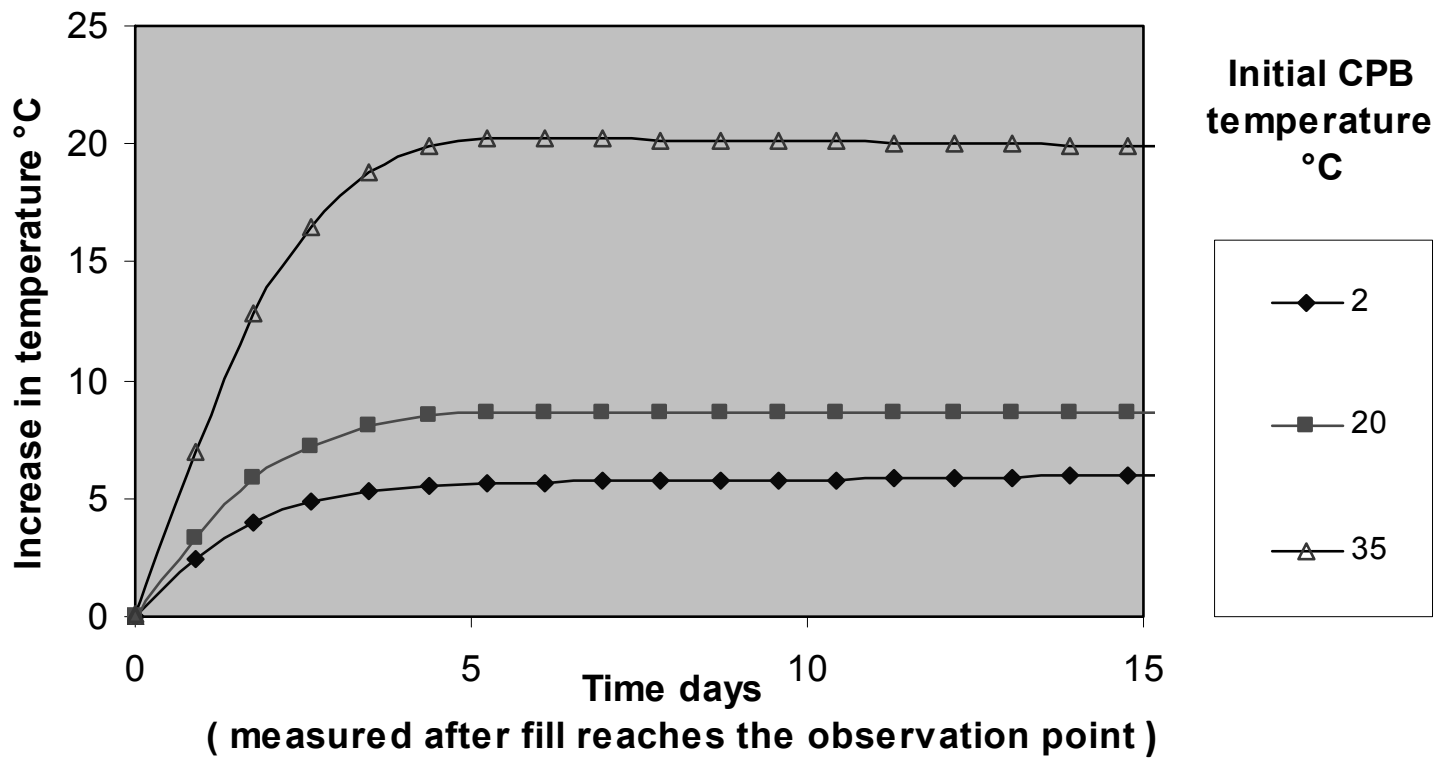

Figure 12 Effect of initial temperature of the CPB on the increased temperature of CPB at $2.5 \mathrm{~m}$ above the bottom of the stope 


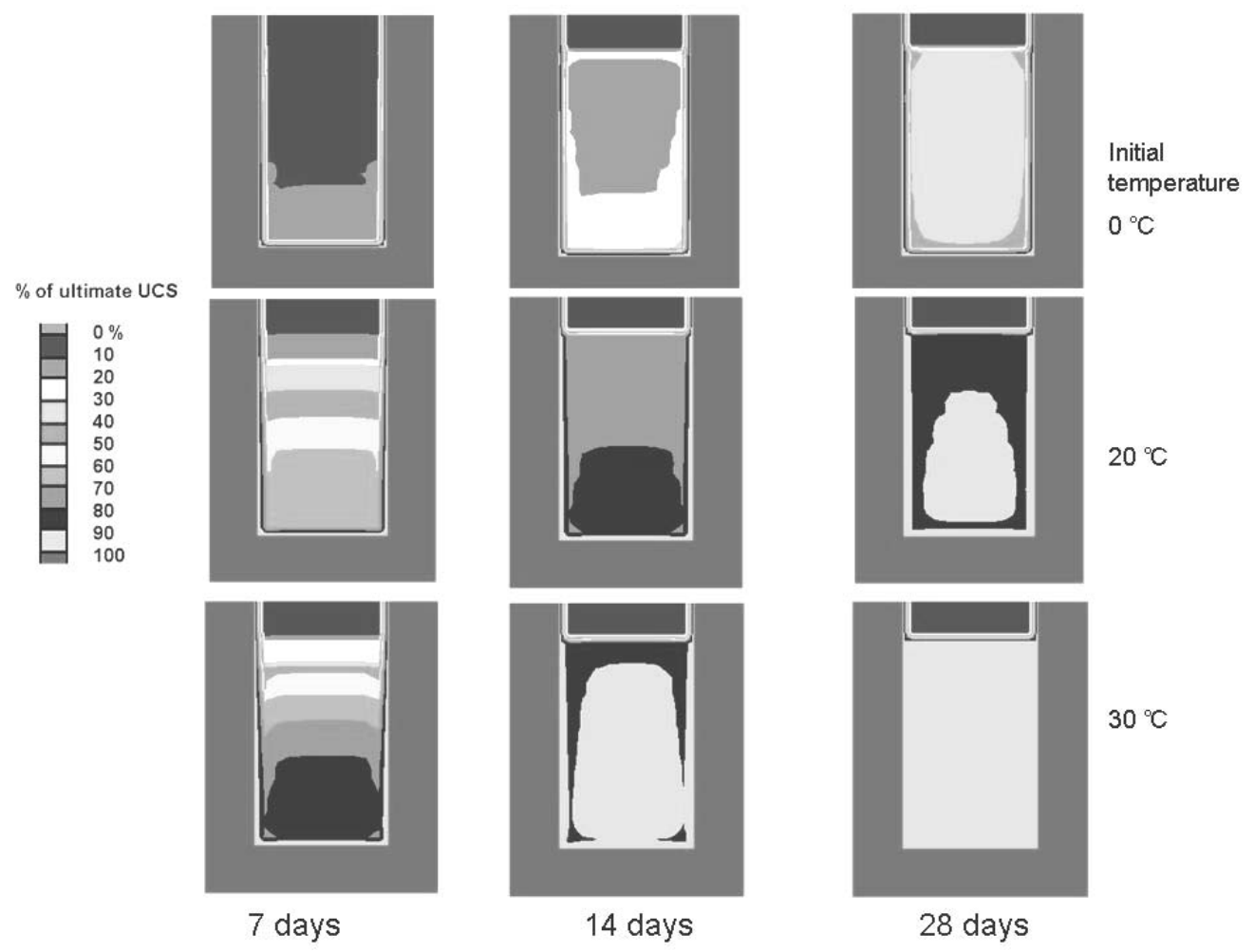

Figure 13 UCS development for different initial CPB temperatures (mix characteristics per Fall and Samb, 2006; rate of backfilling $2.5 \mathrm{~m} / \mathrm{day}$ )
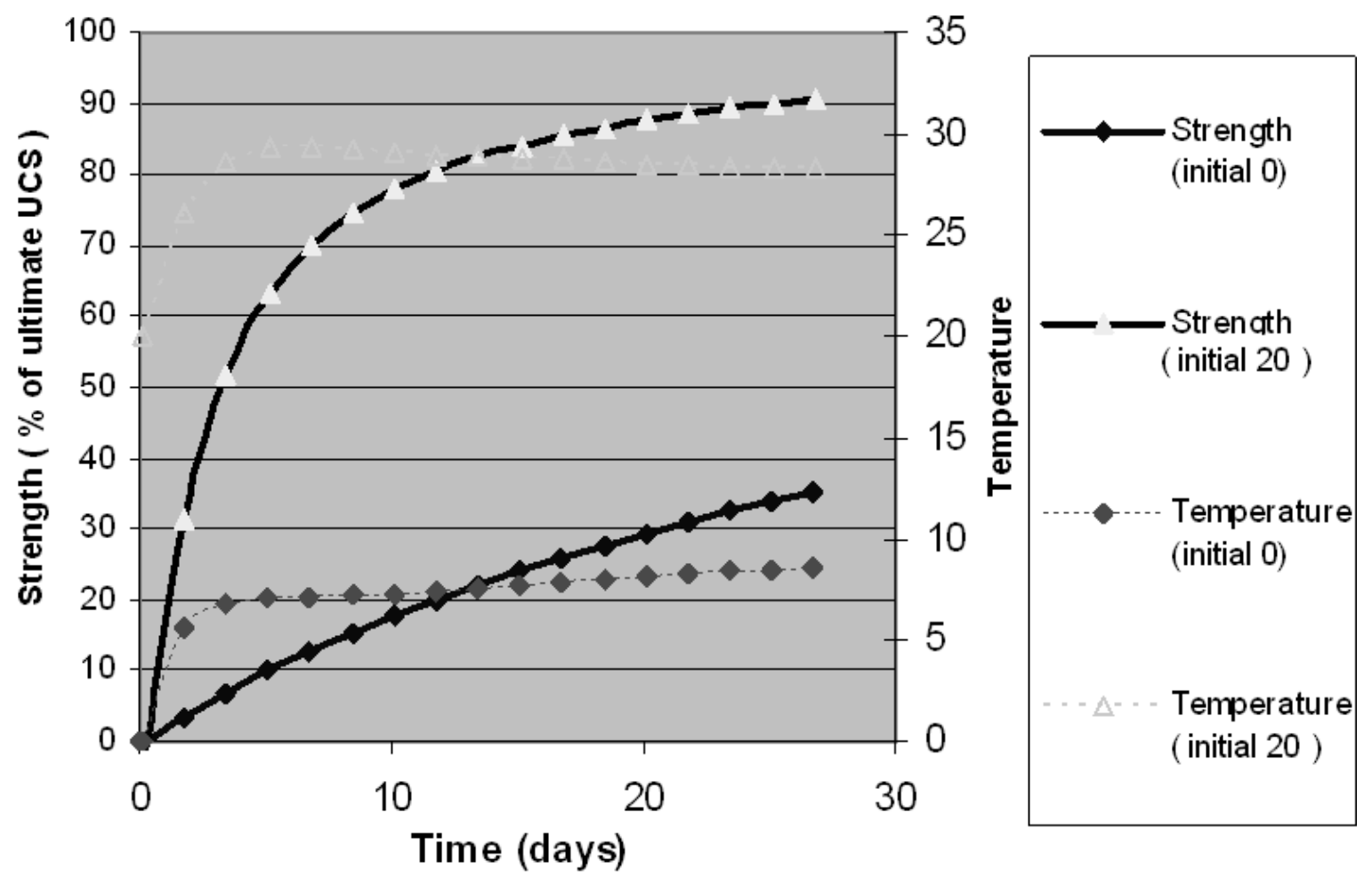

Figure 14 UCS development for different initial CPB temperatures 


\section{$4 \quad$ Summary and conclusions}

In this paper, a TCM model is proposed to analyse and predict the development and distribution of temperature and strength development within CPB structures, and heat transferred by CPB structures under various boundary conditions. Based on the results obtained from this study, the following conclusions can be drawn. First, the model developed for this study is capable of predicting the development and distribution of temperature and strength within undrained $\mathrm{CPB}$ structures reasonably well in comparison to sets of laboratory and field data. Secondly, CPB mix components (e.g. binder content, tailings types), stope size, initial CPB temperature, and filling rate have a significant impact on the development and distribution of strength and temperature within $\mathrm{CPB}$ structures. The developed model can provide useful information on the optimal and safe design of CPB structures. Despite the results obtained in this study, it is also clear that some influencing factors (e.g. consolidation, hydraulic factors, confinement, and damage) should be included in the model.

\section{Acknowledgements}

The writers would like to acknowledge the National Sciences and Engineering Research Council of Canada (NSERC) and the University of Ottawa.

\section{References}

Annor A.B. (1999) A study of the characteristics and behaviour of composite backfill material, Doctor (Ph.D.) Thesis, McGill University, Montreal.

Celestin, J.C. (2008) Performance properties of cemented paste tailings and paste fill barrier systems under various thermal loading conditions, Master (M.A.Sc.) Thesis, University of Ottawa, $222 \mathrm{p}$.

Fall, M. and Nasir, O. (2009) Numerical modeling of the coupled thermo-chemo-mechanical response of cemented paste backfill structures in deep mine temperatures conditions, In Proceedings 3rd Canada-USA Rock Mechanic Symposium and 20th Canadian Rock Mechanic Symposium, [CD-Rom].

Fall, M., Benzaazoua, M. and Ouellet, S. (2004) Experimental characterization of the influence of tailings fineness and density on the quality of cemented paste backfill, Mineral Engineering, Vol. 18, pp. 41-44.

Fall, M., Nasir, O. and Célestin, J. (2007) Paste backfill responses in deep mine temperature conditions, In Proceedings 9th International Symposium of Mining with Backfill, Montreal, Canada.

Fall, M., Benzaazoua, M. and Sae, E. (2008) Mix proportioning of underground cemented paste backfill, International Journal of Tunnelling and Underground Space Technology, Vol. 23, pp. 80-90.

Fall, M. and Samb, S. (2006) Influence of curing temperature on strength, deformation behaviour and pore structure of cemented paste backfill properties at early ages, Construction Building Materials, doi:10.1016/j.conbuildmat.2006.08.010.

Itasca Consulting Group (2005) FLAC Version 5.0, Fast Lagrangian Analysis of Continua, Third Edition, April 2005.

Kesimal, A., Yilmaz, E., Ercikdi, B., Alp, I. and Deveci, H. (2005) Effect of properties of tailings and binder on the short-and long-term strength and stability of cemented paste backfill, Materials Letters, Vol. 59(28), pp. 3703-3709.

Nasir, O. and Fall, M. (2009a) Modeling the heat development in hydrating CPB structures, Journal of Computer and Geotechnics, Vol. 36, pp. 1207-1218.

Nasir, O. and Fall, M. (2009b) Coupling binder hydration, temperature and compressive strength development of underground cemented paste backfill at early ages, Journal of Tunneling and Underground Space Technology, Vol. 25, pp. 9-20.

Perron, R. (1996) Development of an equation for the uniaxial compressive strength of cemented paste mineral materials containing reactive and non-reactive fines, Master (M.A.Sc.) Thesis, Laurentian University, Sudbury, Canada.

Pokharel, M. (2008) Geotechnical and environmental response of paste tailings systems to coupled thermo-chemical loadings, Master (M.A.Sc.) Thesis, University of Ottawa, Canada, 248 p.

Williams, T.J., Denton, D.K., Larson, M.K., Rains, R.L., Seymour, J.B. and Tesarik, D.R. (2001) Geomechanics of Reinforced Cemented Backfill in an Underhand Stope at the Lucky Friday Mine, Mullan, Idaho, U.S. department of Health and Human Services.

Yilmaz, E., Kesima, A. and Ercidi, B. (2004) Strength development of paste backfill simples at Long term using different binders, In Proceedings 8th Symposium MineFill04, China, pp. 281-285. 